\title{
LA CUESTIÓN SOCIOSANITARIA EN LA OBRA DE MARAÑÓN EN EL CONTEXTO DE LA LUCHA CONTRA LAS ENFERMEDADES INFECCIOSAS
}

\author{
Antonio López Vega
}

Universidad Complutense de Madrid

\begin{abstract}
RESUMEN
Como es conocido, Gregorio Marañón y Posadillo (1887-1960), jugó un papel fundamental en el nacimiento de la Endocrinología en España. Sin embargo, su trabajo médico también se centró en otros importantes campos. Fue, sobre todo, en la década de 1910 y 1920, cuando Marañón centró su atención en la situación sociosanitaria de Madrid, probablemente relacionada con su vinculación profesional al tratamiento de las enfermedades infecciosas puesto que desde 1911 se hizo cargo de la Sala de Enfermedades Infecciosas del Hospital General del Madrid, donde tuvo la oportunidad de tratar a este tipo de enfermos. Como consecuencia de su preocupación por la etiología social de enfermedades de prevalencia excesiva o de los brotes epidémicos, en los años siguientes, publicó diversos artículos especializados y presentó comunicaciones en la Real Academia Nacional de Medicina acerca de estas cuestiones vinculadas a la situación sociosanitaria del país. Este trabajo trata de estudiar este aspecto menos conocido de la obra de Gregorio Marañón.
\end{abstract}

PALABRAS CLAVE: Medicina Social. Enfermedades infecciosas. Gregorio Marañón.

\section{SOCIAL-SANITARY SITUATION IN MARAÑON'S WORK IN THE CONTEXT OF THE FIGHT AGAINST INFECTIOUS DISEASES}

\begin{abstract}
Gregorio Marañón y Posadillo (1887-1960), played a leading role in the birth of Endocrinology in Spain as is well known. However, his medical work included other important and significant fields. Thus, it was specially in the 1910s and 1920s, when Marañón dealt with the social-sanitary situation in Madrid probably due to his professional attachement to the treatment of several infectious diseases and epidemic outbreaks. Actually, since 1911 onwards, he was in charge of the wards of infectious diseases in the Hospital General de Madrid where he had the opportunity of treating an important number of patients suffering from this type of pathology and, as a consequence, in the following years he published several articles in medical journals and presented, in the Royal Academy of Medicine in Spain, some reports on infectious diseases and the Spanish health and social conditions at the time. This paper try to analyze this field of Marañón's social and scientific activity.
\end{abstract}

KEY WORDS: Social Medicine. Infectious diseases. Gregorio Marañón. 


\section{INTRODUCCIÓN}

Los acercamientos históricos a la figura y a la obra de Marañón son bastante numerosos aunque de desigual calidad ${ }^{1} \mathrm{y}$ han analizado diversas facetas de su poliédrica actividad. En trabajos previos hemos tenido la ocasión de abordar, utilizando en parte documentos inéditos, diferentes aspectos de la figura de Marañón como su perfil intelectual, aspectos de su aportación médica o algunas de sus obras históricas ${ }^{2}$. Han sido precisamente estos abordajes y

1 Numerosísimas son las biografías hagiográficas y descriptivas dedicadas al Dr. Marañón. Frente a ellas destaca como acercamiento interpretativo el ensayo biográfico que le dedicó Pedro Laín. Cf. Laín Entralgo, P. (1969), Gregorio Marañón. Vida, obra y persona, Madrid, Espasa-Calpe; también, recientemente, LóPEZ VEGA, A. (2011), Gregorio Marañón. Radiografia de un liberal, Madrid, Taurus. La obra médica de Marañón ha sido estudiada por algunos de los mejores especialistas en (2003), Revisión de la obra médica de Marañón (ROMM), Fundación Gregorio Marañón, Ciudad Real. En este trabajo la mayoría de los capítulos están dedicados a cuestiones relacionadas con la endocrinología («Marañón y el tiroides», «Gordos y flacos», «Alimentación», «Gastronomía y salud», «Marañón y la biología sexual», «El crecimiento y su estudio en la época de Marañón», «La diabetes mellitus en la obra del Dr. Gregorio Marañón», «Marañón y las cápsulas suprarrenales», «Las insuficiencias pluriglandulares en el pensamiento de Marañón», «Hipotálamo e hipófisis», «Contribución de Marañón a la teoría de la emoción», «Gregorio Marañón y los reumatismos», «La edad crítica y el climaterio de la mujer y el hombre»). Además, hay un capítulo dedicado a la cuestión aquí tratada: BoUZal, E., Perea, E., Pizazo de la Garza, J. y Rodríguez-Torres, A. (2003), Contribuciones e influencia de Gregorio Marañón en las enfermedades infecciosas. En ROMM, pp. 371-395. Estos especialistas en microbiología apuntan lo que supusieron los trabajos de Marañón en dolencias como la gripe y otras enfermedades virales; los albores del tratamiento de las sífilis; el tifus exantemático; la fiebre tifoidea; fiebre, febrícula y sepsis de origen dentario; o las infecciones del sistema nervioso central. Por ello, nos remitimos a este trabajo para las cuestiones estrictamente clínicas o desde el laboratorio y la bacteriología centrándonos en su aportación a las luchas sanitarias relativas a las enfermedades infecciosas.

2 En relación a su ubicación en el universo intelectual de su tiempo, cf. LóPEZ VEGA, A. (2008a), Estudio introductorio. En LóPEz VEGA, A. (ed.), Epistolario inédito: Marañón, Ortega, Unamuno, Espasa Calpe, Madrid, pp. 14-87. Para la cuestión médica y académica, cf. LóPEZ VegA, A. (2005), Marañón, académico, Biblioteca Nueva, Madrid; LóPEZ VegA, A. (2009), Gregorio Marañón y el nacimiento de la endocrinología en España: Ejemplo ilustrativo del impulso científico del primer tercio del siglo XX español, Circunstancia. Revista de Ciencias Sociales del Instituto Universitario José Ortega y Gasset, 19, disponible en: http://www.ortegaygasset.edu/fog/ ver/966/circunstancia/ano-vii---n--19---mayo-2009/miscelanea/gregorio-maranon-y-el-nacimientode-la-endocrinologia-en-espana--ejemplo-ilustrativo-del-impulso-cientifico-del-primer-tercio-delsiglo-xx-espanol (consultado el 28-07-2011); LÓPEZ VEGA, A. (2007), Marañón y la JAE-CSIC: Un caso atípico, Circunstancia. Revista de Ciencias Sociales del Instituto Universitario José Ortega y Gasset, 14, disponible en: http://www.ortegaygasset.edu/fog/ver/225/circunstancia/ano-v---n-- 
la revisión sistemática de la historiografía consagrada al autor lo que nos ha llevado a considerar que, hasta ahora, no ha sido subrayada suficientemente su implicación y sus aportaciones en el ámbito de los problemas médicosociales de su entorno, tema estrella de muchos de los estudios sobre historia social de la medicina española contemporánea. A través de un análisis exhaustivo de su copiosa producción impresa, pretendemos contribuir a la mejor comprensión del papel jugado por los médicos en las cuestiones de índole médico-social, a través del testimonio de una figura tan emblemática como la que nos ocupa. Nuestra hipótesis de partida es que la cercanía de Marañón a estos problemas se inició a través del contacto directo con los pacientes aquejados de enfermedades infecto-contagiosas, con toda la constelación de factores etiológicos de tipo biológico pero también de tipo social, subyacentes a éstas y que paulatinamente entró a formar parte del grupo de médicos que, en las últimas décadas del siglo XIX y el primer tercio del XX, denunciaron, en nombre de la higiene y de la recién estrenada medicina social, situaciones de desigualdad y conminaron a los poderes públicos para que tomaran medidas para resolverlas.

Cuando Gregorio Marañón y Posadillo (1887-1960) finalizó su carrera universitaria en 1909 y obtuvo el Premio Extraordinario de Licenciatura, se enfrentó con la difícil decisión de hacia donde orientar sus pasos profesionales $^{3}$. Como algunos de los estudiantes universitarios más brillantes, formó parte del colectivo que realizó viajes de ampliación de estudios pensionados fuera de España ${ }^{4}$. Llegado en 1910 a Alemania, se desplazó a Francfort, donde entró en contacto con la bibliografía extranjera y conoció las corrientes de

14---septiembre-2007/ensayos/maranon-y-la-jae-csic--un-caso-atipico (consultado el 28-072011); LóPEZ VeGA, A. (2004), Aportación al vocabulario científico técnico de Gregorio Marañón, Cuadernos de Historia Contemporánea, 26, pp. 215-225. Para facetas de su obra historiográfica, entre otras: LÓPEZ VEGA, A. (2008b), Introducción. En MARAÑóN, G., Amiel. Don Juan, Espasa Calpe, Austral, pp. 13-57.

3 Archivo Histórico Universidad Complutense de Madrid (en adelante Archivo Histórico UCM), Caja 406. Expediente Marañón y Posadillo, Gregorio. También en Archivo General de la Administración (en adelante AGA). Educación. Caja 31/16127, Legajo 910/58. En su licenciatura obtuvo ocho Matrículas de Honor, tres Sobresalientes, nueve Notables y siete Aprobados. En aquella época el premio extraordinario se obtenía tras un examen entre los mejores alumnos de cada promoción — en su caso el tema fue «Tratamiento quirúrgico de los derrames pleurísticos»-

4 Como es bien conocido, la mayoría de ellos iban pensionados por el Ministerio de Instrucción Pública — caso de Marañón — o por instituciones como la Junta para la Ampliación de Estudios, creada con este fin en 1907. 
investigación científica más vanguardistas ${ }^{5}$. Allí trabajó en el Laboratorio de Investigaciones Biológicas que dirigía Paul Ehrlich - que terminaba por entonces sus trabajos con el 606 que supusieron un hito fundamental en el combate contra la sífilis-, y también estuvo adscrito al Laboratorio de Química Fisiológica donde conoció al fisiólogo Gustav Embden, director de dicha institución ${ }^{6}$. Ehrlich le entregó unos gramos de salvarsán (preparado 606) para que estudiase su uso en el combate contra el tifus exantemático, enfermedad prevalente en la España de la época. Así lo recordó Marañón varias décadas después,

en los comienzos de la era salvarsánica se suponía que estábamos a punto de resolver el tratamiento de las enfermedades infecciosas. Ehrlich tenía mucho interés en conocer los resultados de su nuevo remedio, en la viruela y en el tifus exantemático, enfermedades que, por entonces, existían aún en España. Le prometí ocuparme del problema. Y como preparación a la empresa, empleé casi todo mi tiempo en el estudio biológico de las infecciones. [...]

Fracasaron los ensayos en las infecciones exantemáticas. Poco después el gran Nicolle, en Túnez, confirmaba estos resultados negativos. Pero la experiencia me hizo ahondar en la clínica epidemiológica, y a poco me vi nombrado director del Hospital de Infecciosos, que por entonces se empezó a construir en Madrid.

Dividí mi tiempo entonces entre esta labor y el cultivo de mis estudios endocrinos, que inicié de estudiante, en la Sala de Disección y en el Laboratorio de Fisiología, y que ya no había de abandonar?

Así fue. Marañón regresó a Madrid, finalizó su doctorado y elaboró su tesis doctoral, La sangre en los estados tiroideos, por la que obtuvo el Premio

5 Desde entonces fue frecuente su relación con profesores e investigadores extranjeros. El principal motivo de la misma fue, obviamente, el intercambio de publicaciones y la presentación mutua de discípulos. Esta relación de Marañón con destacados científicos está documentada en su epistolario recogido en la Fundación Ortega y Gasset-Gregorio Marañón donde se encuentran cartas y documentos de Walter Cannon, Nicola Pende o Bernard Houssay, entre otros.

6 Archivo Real Academia Nacional de Medicina (en adelante Archivo RANM). Expediente Gregorio Marañón. Consecuencia de su experiencia médica en Alemania son sus publicaciones: MARAÑÓN, G. (1910a), La quemoterapia moderna. Tratamiento de la sifilis por el 606, Madrid, Vidal; MARAÑón, G. (1910b) La quemoterapia moderna. El nuevo remedio de Ehrlich-Hata contra la sífilis, Revista Clínica Médica, 4, pp. 203-217; MARAÑóN, G. (1911), Acción del arsenobenzol en las enfermedades no sifilíticas, Revista Clínica de Madrid, 5, pp. 295 y ss.

7 Marañón, G. (1968a), Discurso al ser nombrado miembro de la Sociedad Peruana de Neuropsiquiatría el 7 de septiembre de 1939. En Obras Completas (en adelante OC), vol. II , Madrid, Espasa Calpe, p. 392. 
Extraordinario de Doctorado ${ }^{8}$. Poco después, en mayo de 1911, ganó por oposición - en la que obtuvo el número 1 - un puesto de médico de la Beneficencia Provincial. Entonces, en lugar de pasar a formar parte del equipo de un médico de número, solicitó como destino el servicio de las salas de enfermedades infecciosas - cuya jefatura estaba entonces vacante-, situado en unas salas abuhardilladas en la última planta del Hospital General de Madrid, donde trabajó hasta 1913. En aquellas salas, como consecuencia de las deficientes condiciones higiénicas, los contagios se multiplicaban. En los dos primeros años en que se ocupó de las enfermedades infecciosas, Marañón se ayudó del material que se utilizaba para realizar autopsias en el hospital y del que se empleaba en el laboratorio que dirigía Tomás Maestre, catedrático de Medicina Legal ${ }^{9}$. En 1913, ayudado por Sor Ventura Pujadas - superiora del Hospital-y por la marquesa de Perinat, inauguró un pabellón de infecciosos, situado en el patio central de dicho Hospital General ${ }^{10}$. Allí desarrolló su trabajo sobre enfermedades infecciosas hasta que, en 1925, se finalizaron las obras del Hospital del Rey donde se trataría a estos enfermos - por lo que, en tiempos republicanos, recibió el nombre de Hospital de Enfermedades Infecciosas (hoy Instituto de Salud Carlos III de Madrid) - . El 9 de octubre de 1912, solicitó al Ministro de Instrucción Pública que se le permitiera presentarse a una plaza de auxiliar del sexto grupo de la facultad de Madrid, auxiliaría que obtuvo. Desde entonces quedó vinculado a la Universidad a través de la ayudantía de la sala de disección adscrita a la cátedra de Federico Olóriz ${ }^{11}$.

8 Archivo Histórico UCM, Caja 406. Expediente Marañón y Posadillo, Gregorio. También en AGA, Educación, Caja 31/16127. Legajo 910/58. Las asignaturas que cursó en 190910 fueron: Historia de la Medicina (Notable), Análisis Químico, Antropología y Psicología Experimental (Aprobado). El 20 de enero de 1911 defendió su tesis doctoral obteniendo la calificación de Sobresaliente. Se conserva una fotocopia de la misma en el Archivo de la Fundación Ortega y Gasset-Gregorio Marañón (en adelante FOM).

9 Archivo RANM. Expediente Gregorio Marañón.

10 El pabellón de infecciosos era, según algunos testimonios, un lugar decoroso aunque no lujoso. Allí, anteriormente, se habían almacenado enseres hospitalarios. Construido en madera, el principal beneficio que se obtuvo para los enfermos con este traslado, fue la mejora higiénica. Aspectos relatados en (1935), Veinticinco años de labor. Historia y bibliografia del Profesor G. Marañón y del Instituto de Patología Médica del Hospital de Madrid, Madrid, Espasa-Calpe. También reflejados por GómEZ-SAnTOS, M. (2001), Gregorio Marañón, Barcelona, Plaza \& Janés, pp. 81-82.

11 AGA, Educación, Caja 31/16127. Legajo 910/58. También Legajo 15050/12. La normativa acerca de estas auxiliarías estuvo recogida en la Gaceta de Madrid en el RD de 12 de enero de 1912 y en la RO de 12 de octubre de ese mismo año. En 1924, presentó una instancia donde solicitaba ser nombrado profesor agregado de Patología y Clínica Médica, lo que fue 
En los años siguientes, Marañón llevó a cabo un trabajo febril. Publicó entonces más de una treintena de trabajos especializados que le valieron un gran prestigio profesional como por ejemplo, además de diferentes artículos, el Manual de Medicina Interna (dirigido por él junto a Teófilo Hernando y cuya publicación se inició en 1916), La Edad Crítica (1919) o La diabetes insípida. Nuevas orientaciones sobre su patogenia y tratamiento (1920). En 1920 publicó sus primeros artículos sobre el mecanismo de la emoción - «La emoción» $\mathrm{y}$ «La reacción emotiva a la adrenalina»—, que, como ha señalado Antonio Fernández de Molina «tanto contribuyó a la incorporación de Marañón a la literatura científica mundial $\rangle^{12}$. Y ya en los años veinte su discurso de ingreso en la Real Academia de Medicina Estado actual de la doctrina de las secreciones internas (marzo de 1922), La evolución de la sexualidad y los estados intersexuales (1930), o diferentes obras de alta divulgación científica como Gordos y flacos (1926) o Tres ensayos sobre la vida sexual (1926). En todo caso el prestigio profesional que atesoró vino avalado, además, por su participación en la Real Academia Nacional de Medicina, donde en 1909 recibió el premio Martínez Molina y en 1914 el premio Álvarez Alcalá por sus monografías Investigaciones anatómicas sobre el aparato paratiroideo del hombre y Las glándulas de secreción interna y las enfermedades de la nutrición, respectivamente ${ }^{13}$. Su relevancia científica le llevó a participar en

resuelto positivamente por la junta de la Facultad el 30 de junio de ese año (Marañón se acogía a lo dispuesto en el artículo 4 del RD de 30 de septiembre de 1902. El 16 de julio de 1924 el Vicerrector envió una nota al Subsecretario del Ministerio de Instrucción Pública notificándole la decisión de la Junta. El 20 de agosto de 1924, desde el Ministerio se notificó el nombramiento por RO puntualizando que era «gratuito y no da más derecho al nombrado que los que le reconocen los Reales decretos mencionados»). Posteriormente, al llegar la II República, fue nombrado, también por Decreto, catedrático de Endocrinología en el verano de 1931.

12 MARAÑón, G. (1920a), La emoción, Voluntad, 15 de marzo de 1920; MARAÑóN, G. (1920b), La reacción emotiva a la adrenalina, La Medicina Íbera, 14 de agosto de 1920. Antonio Fernández de Molina explica que su interés por la emoción nació de sus experiencias con adrenalina inyectada a humanos, lo que le llevó a establecer importantes conceptos que integrará en su teoría neurohumoral de la emoción. Véase FernÁndEZ DE MolinA, A. (2003), Contribución de Marañón a la teoría de la emoción. En ROMM, pp. 349-369.

13 La obtención del premio Martínez Molina suponía título de académico correspondiente de la medicina amén de la dotación económica (2.561 pesetas) (Archivo RANM. Gregorio Marañón). Desde entonces, asistió a las sesiones ordinarias de la Academia y participó en alguno de sus debates, dándose a conocer entre los médicos que formaban la Corporación. Por otra parte, la obra por la que obtuvo el premio Álvarez Alcalá, adelantaba algunos de los puntos esenciales de la teoría pluriglandular, de la que fue pionero junto a Nicola Pende, Émile Gley y Ernest Henry Starling, y que iba a ser el eje sobre el que iba a desarrollar su investiga- 
diferentes asociaciones médicas y científicas y a ocupar un papel central en el panorama médico y social de la época, especialmente, desde 1918 cuando fue comisionado por el Gobierno, junto a Ruiz Falcó y Gustavo Pittaluga, para estudiar la etiología de la pandemia gripal que asolaba España y Europa. Desde entonces amplió el campo de sus inquietudes comenzando a publicar escritos sociales y políticos en las páginas de El Liberal, periódico vinculado a la familia de su mujer, Dolores Moya, en el que escribió diferentes artículos en los que se plasmó su pensamiento social, según ha señalado Pedro Laín ${ }^{14}$.

De este modo, en los años que llevarían hasta su nombramiento de catedrático de Endocrinología en el verano de 1931, la obra y pensamiento médico de Gregorio Marañón giró, fundamentalmente, en torno a dos grandes áreas, la endocrinología y las enfermedades infecciosas ${ }^{15}$.

\section{PREOCUPACIÓN SOCIOSANITARIA DE MARAÑÓN}

La preocupación de Marañón por la lucha contra las enfermedades infecciosas le llevó a solicitar a los poderes públicos una serie de reformas sociales y de medidas de salud pública, necesarias para minimizar la incidencia de las epidemias que estaban haciendo estragos en España en general pero, de modo muy particular, en el Madrid de la época. Por otro lado, esta sensibilidad del autor hacia las cuestiones sociales que incidían en el origen y desarrollo de las enfermedades infecto-contagiosas, no fue algo peculiar de Marañón sino que se inserta en el marco más amplio de los estudios sobre el papel social de la medicina y la relación expresa de la medicina con la cuestión social nacida de la industrialización, que ha sido abordada tanto desde la perspectiva global del nacimiento de la medicina social ${ }^{16} \mathrm{y}$ las luchas sanitarias como instrumen-

ción endocrinológica en las décadas venideras. Esta teoría consistía, grosso modo, en el análisis de la participación de las glándulas endocrinas o de secreción interna — tiroides, hipófisis, suprarrenales, genitales, etc.- en diferentes procesos metabólicos humanos —nutrición, crecimiento, sexualidad, senectud, etc.-.

14 Laín Entralgo (1969), pp. 36-38.

15 Para Marañón endocrinólogo, cf. ROMM y LóPEZ VEGA (2009).

16 Rodríguez OCAÑA, E. (2002), La medicina como instrumento social. En PERDIGUERo, E. y CASTEJÓN, R (eds.), La acción social de la medicina y la construcción del sistema sanitario en la España contemporánea, Trabajo social y salud, n. ${ }^{\circ}$ monográfico, pp. 5-242. RoDRÍGUEZ OCAÑA, E. (2005), Salud pública en España. Ciencia, profesión y política, siglos XVIII$X X$, Granada, Universidad de Granada. 
to de acción social ${ }^{17}$, como en los estudios monográficos sobre aspectos particulares como el problema de la gripe ${ }^{18}$, de la tuberculosis ${ }^{19}$, las enfermedades venéreas ${ }^{20} \mathrm{o}$ la mortalidad infantil ${ }^{21}$, entre otras.

En el análisis de esta cuestión nos vamos a fijar en dos cuestiones. En primer lugar, analizaremos algunas de sus reflexiones acerca del origen de las epidemias y sobre la necesidad de mejoras higiénicas. En segundo lugar, nos detendremos en algunos de sus trabajos e iniciativas en la lucha contra estas enfermedades, fijándonos especialmente en su participación en la lucha contra la pandemia gripal de 1918 y, en su iniciativa por la mejora sociosanitaria de la región extremeña de Las Hurdes - cuyo punto culminante fue el famoso viaje que realizó junto a Alfonso XIII en junio de 1922-.

\subsection{Reflexiones acerca de la situación sociosanitaria}

Como es sabido, desde el último tercio del siglo XIX, la preocupación higienista fue una de las principales líneas de acción de los pensadores influidos por los principios krausistas e institucionistas. A principios del siglo XX, esta preocupación se había extendido entre los principales intelectuales españoles, desde los regeneracionistas hasta los miembros de la generación del 14. En estos años, una de las principales tareas que asumieron los médicos higienistas fue la de convencer a las autoridades públicas de la necesidad de instaurar e implantar medidas que facilitaran la salubridad de las ciudades.

En concreto, Marañón puso el acento en la necesidad de esas medidas políticas y en la responsabilidad de los médicos y de las facultades de medicina en el tratamiento correcto de las epidemias. Respecto a lo primero, Marañón

17 Rodríguez OcAÑA, E. y Molero MesA, J. (1993), La cruzada por la salud. Las campañas sanitarias del primer tercio del siglo XX. En MONTIEL, L. (coord.) La salud en el Estado de Bienestar. Análisis histórico, Madrid, Ed. Complutense, pp. 133-148.

18 Porras Gallo, Mª.I. (1997), Un reto para la sociedad madrileña. La epidemia de gripe de 1918-19, Madrid, CAM-Ed. Complutense.

19 Molero Mesa, J. (ed.) (1987), Estudios médico-sociales sobre la tuberculosis en la España de la Restauración, Madrid, Ministerio de Sanidad. Colección Clásicos de la Salud pública.

20 CASTEJón Bolea, R. (2001), Moral Sexual y enfermedad. La medicina española frente al peligro venéreo (1868-1936), Granada, Universidad de Granada.

21 Rodríguez OCAÑA, E. (1996), Una medicina para la infancia. En Borras Llop, J.M. (ed.) Historia de la infancia en la España contemporánea, Madrid, Ministerio de Trabajo y Asuntos sociales y Fundación G. Sánchez Ruipérez, p. 149-183. 
solicitó a los poderes públicos la aplicación de una serie de reformas sociales y medidas de salud pública para que se produjera una menor incidencia de las epidemias que afectaban a la España de la época. Fue sobre todo en los años de 1918 - consecuencia, fundamentalmente, de su viaje a Francia en comisión con motivo de la pandemia gripal a la que nos referiremos más adelante- y 1919 cuando Marañón se ocupó de difundir en la opinión pública la necesidad de una mejora higiénica y sanitaria, basada en la convicción de la necesidad de dotar de un mayor nivel educativo y cultural al pueblo español. Desde entonces, se refirió con asiduidad a la necesidad de crear una conciencia general acerca de la higiene pública y privada. En un artículo publicado en 1920 en El Liberal lamentaba que los políticos — todos en general, pero daba una mayor responsabilidad a los de significación ideológica de izquierda por su mayor sensibilidad social — no priorizaran en su acción política la cuestión higiénica, índice evidente de civilidad. La ignorancia general respecto a cuestiones sanitarias debía atajarse mediante una iniciativa política y pública. Los médicos y sectores sanitarios, por sí solos, no podían hacer nada ${ }^{22}$.

Para Marañón uno de los problemas fundamentales era «el estado bochornoso de los mendigos, desocupados y golfos en Madrid» ${ }^{23}$. La mendicidad había proliferado en la capital desde las últimas décadas del siglo XIX como consecuencia del aumento demográfico. Diferentes intelectuales habían denunciado la situación que se derivaba del estado hacinado en el que se encontraban miles de personas en la ciudad - recuérdense, por ejemplo, las descripciones que del mundo del hampa madrileña había realizado Pío Baroja, concretamente en su trilogía La lucha por la vida-. Marañón también se había referido al aumento de población extraordinario que se había producido en Madrid en las últimas décadas y a cómo se asistía de modo impasible, por parte de las autoridades y del pueblo, al aumento de la miseria ${ }^{24}$.

22 MARAÑón, G. (1968b), «El peligro del tifus», El Liberal, 20 de julio de 1920. En OC, vol. IV, pp. 33-34.

23 MARAÑón, G. (1968c), «El tifus exantemático», El Liberal, 19 de septiembre de 1920. En $O C$, vol. IV, p. 35-36.

24 Con respecto a las condiciones sociosanitarias de Madrid, la obra de referencia es la del médico húngaro afincado en España, Philipp Hauser, vid. CARRILlO, J.L. (ed.) (1996), Entre Sevilla y Madrid. Estudios sobre Hauser y su entorno, Sevilla, Imp. A. Pinelo. El estudio de Porras Gallo, M. ${ }^{a}$ I. (2002), Un acercamiento a la situación higiénico-sanitaria de los distritos de Madrid en el tránsito del siglo XI al XX, Asclepio, 54 (1), 219-250, es de referencia obligada con inclusión de todas las fuentes que se ocupan de este tema en el periodo analizado, desde la conocida obra de Revenga y la citada de Hauser. Por otro lado, en el trabajo se contrastan los datos de morbilidad y mortalidad de estas fuentes médicas impresas con los 
En este sentido, Marañón consideraba prioritario la resolución de este problema. Censuraba el modo caritativo en que se entendía la mendicidad en Madrid, asunto que debía abordarse «con una técnica enérgica y bien conocida. No es un problema de caridad, sino un problema estrictamente científi$\operatorname{co»}{ }^{25}$. La solución no era la caridad, era, simplemente, justicia social. De este modo era «el Estado [quien] debiera organizar la defensa del hombre enfermo y mísero» ${ }^{26}$. En 1921, criticó que en el Senado se negara la existencia de la mendicidad real y se abogase por la persecución y confinamiento de la mendicidad profesional como modo de acabar con el problema. Denunciaba la tesis que sostenía que la pobreza existía porque los mendigos no tenían otra opción. Su persecución por parte de las autoridades no era la solución. Por el contrario, en su opinión, los poderes públicos debían construir comedores públicos, asilos, casas de acogida, etc. Madrid tenía pobres que morían por inanición, era una ciudad donde la miseria y el abandono estaban a la orden del día ${ }^{27}$. Este tema de la recolección de indigentes venía coleando desde varios años antes. Con motivo de la visita que algunas autoridades habían hecho a un suburbio madrileño en 1919, Marañón había denunciado la práctica común de recoger a los pobres de la calle y su traslado a campamentos de desinfección donde, en lugar de ser desinfectados y tratados de modo correcto desde el punto de vista sanitario, eran hacinados ${ }^{28}$. Esta situación, además de hambre, generaba focos de infección y era origen de epidemias que afectaban a toda la ciudad. Marañón criticaba la ignorancia higiénico-sanitaria de los gobernadores civiles y de sus consejeros técnicos. Además señalaba cómo los empleados de esos campamentos o por miedo o por conveniencia, ocultaban la situación de hacinamiento de aquellos indigentes. Sólo si se garantizaban buenas condiciones para los indigentes era lícita su recogida de las calles. Mientras no se les tratase bien, con dignidad, - $-\mathrm{y}$ señalaba que había que alimentarlos, vestirlos adecuadamente y desinfectarlos-, su recogida era condenable desde el punto de vista sanitario y ético. Desde el punto de vista sanitario, Marañón llamaba a seguir el ejemplo alemán. Allí todos los enfer-

relativos a las Estadísticas demográfico-sanitarias del Ayuntamiento y del Ministerio de Gobernación.

25 MARAÑÓN (1968c).

26 MARAÑón, G. (1968d), El problema de los hospitales, El Liberal, 5 de noviembre de 1920. En $O C$, vol. IV, pp. 39-40.

27 Marañón, G. (1968e), Los muertos de hambre, El Siglo Médico, 9 de julio de 1921. En $O C$, vol. IV, pp. 47-48.

28 Marañón, G. (1968f), Sobre la represión de la mendicidad, El Siglo Médico, 15 de noviembre de 1919. En $O C$, vol. IV, pp. 23-25. 
mos eran tratados por los poderes públicos con todas las garantías sanitarias. Por eso, lamentaba que los políticos españoles no siguiesen ese modelo sanitario y, en concreto, censuraba la actitud de los socialistas españoles que, según él, no se habían ocupado seriamente de la situación de los pobres en los hospitales de Madrid ${ }^{29}$.

En esta misma línea, solicitó condiciones dignas de veraneo para los niños pobres $^{30}$. Como sabemos, desde que la Institución Libre de Enseñanza había impulsado una serie de medidas educativas en pos de una educación integral de los niños y jóvenes - amén de conocimientos, se les inculcaba amor a la naturaleza, nociones de higiene, la conveniencia de la gimnasia, etc.- , se había extendido entre los intelectuales de raigambre liberal la bondad pedagógica y formativa de esas medidas. En esta línea y dentro del contexto que estamos relatando, Marañón solicitó que el Estado garantizase la salida de Madrid de los niños pobres durante el verano. Desde su experiencia médica afirmaba que, en muchos casos, ésta era una necesidad apremiante para garantizar la salubridad de esos niños y de las ciudades. En realidad, ésta era una medida que la Inspección General de Sanidad ya organizaba. Los niños con recursos insuficientes realizaban salidas estivales a las localidades gallegas de Oza dos Ríos y Pedrosa, pudiendo ver por vez primera el mar — este tipo de actividades y salidas de Madrid se habían popularizado con las famosas colonias de verano llevadas a cabo por los institucionistas en la localidad cántabra de San Vicente de la Barquera desde finales del siglo XIX - . Sin embargo, y éste era el motivo de su crítica desde las páginas de El Liberal, en aquel verano de 1921, el Ayuntamiento de Madrid aún no había designado a los beneficiarios de esas vacaciones tan necesarias.

Entre otras medidas sanitarias por las que abogó el médico, destaca su participación en la promoción de la sierra de Gredos como lugar propicio para la salud de los madrileños ${ }^{31}$. En 1919, la Comisaría Regia del Turismo y Cultura Artística, lanzó una campaña que explicaba las bondades de esta cadena montañosa. No deja de ser curiosa esta promoción del turismo de los madrileños

29 MARAÑón, G. (1968g), Los hospitales de Alemania, El Liberal, 22 de septiembre de 1920. En $O C$, vol. IV, pp. 37-38.

30 MARAÑón, G. (1968h), El verano de los niños pobres, El Liberal, 17 de julio de 1921. En $O C$, vol. IV, p. 49.

31 Comisaría Regia del Turismo y Cultura Artística (1919), Yuste y la Sierra de Gredos, Madrid. En la publicación, además de Marañón, participaron el marqués de la Vega Inclán que hizo una loa general de Gredos, Pedro Antonio de Alarcón que disertaba acerca del Monasterio de Yuste y Ramón González y Domínguez que señalaba las posibles excursiones que se podían realizar en dicha Sierra. 
que generaría que, pocos años después, en 1928, se inaugurase allí el primer Parador Nacional de Turismo. Por su parte, Marañón en su «Elogio Médico de la Sierra de Gredos», insistía en los diferentes factores de la vida cotidiana en las grandes urbes que influían en la expansión de las epidemias. De hecho, señalaba que,

la higiene actual exige una inmediata derivación de los ciudadanos hacia el campo. De poco vale la pretendida higiene individual y doméstica dentro de la cloaca inmensa de la ciudad [...] Los pobres y los ricos, allá abajo están todos, revueltos en la misma atmósfera insana que igualmente penetra en las guardillas mezquinas, que en los palacios; y que es más temible por lo mismo que nos pasa desapercibida. Luchamos contra el agua impura, contra los alimentos adulterados o viejos, con tantos enemigos del habitante urbano; y olvidamos el daño mucho mayor que supone la permanencia perpetua dentro del vaho espantoso en que se condensan todas las emanaciones de miles y miles de organismos ${ }^{32}$.

Alabando las virtudes curativas de la sierra de Gredos, llamaba al contacto de los hombres con la naturaleza recogiendo la idea gineriana que, como estamos viendo, valoraba muy positivamente desde el punto de vista médico. Con todo, auspiciaba una mejoría de la salubridad de Madrid si se alentaban desde los poderes públicos las visitas tanto a la sierra de Guadarrama - unida intrínsicamente a la simbología institucionista por los paseos que por allí daba Giner con sus chicos-, como a la de Gredos. Estas escapadas de los madrileños a la naturaleza ayudarían a combatir las diferentes epidemias.

En este aspecto, conviene señalar por último, la interesante aportación que realizó en 1923 en lo que se refiere al tratamiento de estas epidemias. En el período estival durante la estancia familiar en la región francesa de Pontaillac, Marañón escribió su artículo «El error de la epidemiología de las edades y su importancia en la higiene pública» ${ }^{33}$. En él señalaba cómo había observado en la práctica médica de entonces que muchas de estas enfermedades infecciosas - y se detenía a analizar la escarlatina, el sarampión, la tos ferina, la fiebre tifoidea, el tifus exantemático y la tuberculosis pulmonar-, tenían asociada

32 Marañón, G. (1919), Elogio Médico de la Sierra de Gredos. En ComisAría Regia (1919), pp. 75-77.

33 MARAÑÓN, G. (1923a), El error de la epidemiología de las edades y su importancia en la higiene pública, El Practicante Toledano, 15 agosto, pp. 13-16 (Fondos bibliográficos del Centro de Investigaciones Biológicas). El concepto de «portadores sanos» había sido acuñado por Charles Chapin en 1910 y ha sido uno de los planteamientos clave para el conocimiento y control de las enfermedades infecciosas. 
su difusión y desarrollo a determinadas edades. Pues bien, Marañón señalaba que era un error olvidar a los individuos sanos que rodeaban a esos enfermos pues «en las infecciones que atacan con preferencia — por otra parte aparente en muchos casos - a los individuos de una edad determinada, hay que buscar, precisamente en los de las otras edades, los vehículos principales de su propagación, ya bajo la forma de invasiones atípicas y abortadas, ya bajo la de portadores sanos de los gérmenes correspondientes $\rangle^{34}$. Si a ello se añadían las carencias higiénicas de la sociedad española del momento, estas epidemias eran difícilmente controlables por las autoridades sanitarias. Por ello, hacía hincapié en la necesidad de la mejora de la cultura sociosanitaria del país no sólo de las clases más humildes, "sino también al vulgo encopetado de los palacios; peor tal vez éste que aquél, porque une a su ignorancia la pedantería; porque no recibió sus errores del ambiente [...] sino que los adquirió en lecturas mal entendidas y peor digeridas o en el trato con la pseudociencia, que forma tan poderoso estrato en las clases elevadas de la sociedad ${ }^{35}$. Por eso, hacía un llamamiento a los médicos para llevar a cabo una labor de formación higienista entre la sociedad que era, a su juicio, el modo más eficaz para combatir estas enfermedades infecciosas.

Esto nos da pie para abordar la segunda cuestión a la que nos hemos referido más arriba, la responsabilidad de los médicos y de las facultades de medicina en el tratamiento correcto de las epidemias. En este sentido, Marañón entonó el mea culpa e hizo un llamamiento a sus compañeros de profesión para que ejercieran el papel que les correspondía en la lucha sanitaria contra las enfermedades infecciosas. Así, en una conferencia dictada en agosto de 1920, Marañón hizo hincapié en que el principal agente en la lucha contra las enfermedades infecciosas era el mismo médico ${ }^{36}$. Las principales obligaciones de los galenos en este área eran diagnosticar rápidamente la dolencia del enfermo, adoptar medidas profilácticas urgentes y, si ocurría en una ciudad populosa, advertir del brote epidémico a las autoridades y organismos sanitarios. Marañón denunciaba que este protocolo de actuación no se cumplía en la España de entonces. El motivo fundamental de esta negligencia era el evidente retraso de la higiene pública. Para él, los principales culpables de esta inoperancia eran los mismos médicos — cuya ignorancia y desidia era más perni-

34 MARAÑón (1923a), p. 16.

35 MARAÑ́́N (1923a), p. 13.

36 MARAÑón, G. (1920c), El papel del médico práctico en la lucha epidemiológica, La Medicina Íbera, t. 12, vol. 2, nº.149, vol. 3, no. 150 y 151, 11, 18 y 25 de septiembre y 2 de octubre (Conferencia leída en la Semana Médica de Santander en agosto de 1920). 
ciosa que la misma pobreza-, la deficiente organización sanitaria, la inactividad política y el desconocimiento generalizado de las nociones básicas de higiene en las capas sociales más desfavorecidas ${ }^{37}$.

El origen de la falta de preparación de los médicos lo situaba en los estudios universitarios donde, según denunciaba, por lo general, se pasaba muy por encima en los conocimientos acerca de los estados infecciosos. El motivo era el mismo carácter de estas enfermedades que hacía que nunca estuvieran descritas de modo prolijo en los manuales que manejaban los estudiantes. Entonces el diagnóstico clínico de este tipo de enfermedades resultaba complicado - algo que se agravaba aún más en las poblaciones rurales-. En ocasiones su prevención era imposible, o bien por desconocimiento microbiano de algunas de estas enfermedades, o bien porque su sintomatología se manifestaba tardíamente, lo que dificultaba enormemente la prevención de algunas epidemias. Como el diagnóstico clínico —identificación del germen cuando es conocido, o hallazgo de síntomas que caracterizan una patología-, en muchas ocasiones no era viable, Marañón hacía hincapié en la necesidad de mejorar el diagnóstico epidemiológico, esto es, la clasificación por sectores de las enfermedades y sus agentes contagiosos, algo que ya era posible ${ }^{38}$.

Con todo, el mayor perjuicio que sufría la formación de los futuros médicos era el mismo tratamiento que se daba en los hospitales a estas enfermedades. Así, en la mayoría de los casos, estos enfermos no eran tratados en servicios especiales de enfermedades infecciosas - como su Servicio en el Hospital General de Madrid-, sino que estaban distribuidos por las salas de enfermos comunes. Esto era un evidente despropósito pues, además de no ser tratados de modo conveniente, su ubicación en las salas comunes contribuía a

37 El estudio de la pobreza y de las actividades de beneficencia y su significado en la sociedad española, ha sido objeto de importantes trabajos como el de CARASA SoTO, P. (1990), La pobreza y la asistencia en la historiografía española contemporánea, Hispania, 50 (176), pp. $1475-1503$.

38 En esta conferencia Marañón señaló los diferentes grupos de enfermedades infecciosas que se podían agrupar a través del diagnóstico epidemiológico. Proponía: 1- Procesos infectivos que se transmiten por secreciones de las mucosas respiratoria y digestiva; a este grupo pertenecían el sarampión, la escarlatina, la gripe, la coqueluche, la meningitis cerebroespinal y las paperas. 2- Las que se transmiten por contacto directo de la piel del enfermo al sano - viruela, varicela y erisipela - 3- Las que se propagan por las excreciones digestivas del enfermo y tienen como vía principal de difusión la contaminación de las aguas y los productos contaminados por estas - fiebre tifoidea, cólera, disentería bacilar- . 4- Infecciones de epidemiología bien precisada y, por tanto, poco frecuentes - peste aftosa y fiebre de Malta- y, 5- Infecciones transmitidas por parásitos e insectos intermediarios — tifus exantemático, paludismo, peste, fiebre amarilla, etc. 
la propagación de las epidemias. Marañón lamentaba que no existiera en todas las clínicas un servicio de enfermedades infecciosas bien dotado material y humanamente. Por todo ello, concluía, incoando a que los médicos españoles tuvieran como obligación fundamental conocer los principales datos epidemiológicos de las enfermedades infecciosas que ya se conocían. Este era, a su juicio, una de las principales cuestiones que se debía mostrar a los jóvenes estudiantes de medicina. Dentro de su concepción antropocéntrica de la medicina, el estudiante debía ser consciente del papel social de su profesión en la lucha contra las enfermedades infecciosas. Si los nuevos estudiantes de medicina salían de la facultad convencidos de esa misión social, ya se habría iniciado la regeneración de la higiene pública que se auspiciaba e impulsaba desde hacía varias décadas.

\subsection{Trabajos e iniciativas en la lucha contra las enfermedades infecciosas}

Detengámonos ahora en alguna de las principales aportaciones clínicas que Marañón realizó en el combate de las enfermedades infecciosas. Como hemos mostrado, su interés por este área se vislumbró ya desde su viaje de ampliación de estudios a Francfort en 1910. Uno de los lugares donde Marañón presentó muchos de sus resultados fue en la Academia de la Medicina. En la docta casa presentó varias comunicaciones relacionadas con el combate contra el tifus abdominal, la meningitis cerebroespinal, la erisipela, la fiebre tifoidea, la escarlatina, el tétanos o la tuberculosis, entre otras.

Destaquemos, a modo de ejemplo, algunas de sus aportaciones concretas -infección del sistema nervioso central, tifus exantemático y fiebre tifoidea-, y detengámonos en dos iniciativas concretas en las que tuvo una implicación decisiva: la lucha contra la pandemia gripal ${ }^{39}$ que asoló España y buena parte de Europa en 1918 y su interés por el desarrollo de la región extremeña de Las Hurdes, cuyo punto culminante fue el viaje que realizó con Alfonso XIII en junio de $1922^{40}$.

39 Porras Gallo (1997).

40 No detallamos todas sus aportaciones, porque desde un punto de vista médico están mejor analizadas por los especialistas anteriormente citados en: BOUZAL, PEREA, PIZAZO DE LA GARZA y RodríGUEZ-TORRES (2003), pp. 371-395. Los ejemplos aquí traídos a colación han sido elegidos por distintos motivos. Los dos primeros porque reflejan desde un período tan temprano como 1913 y 1916 el interés que Marañón tuvo por la historia —en este caso por los primeros casos de determinadas enfermedades que se habían producido en tiempos pretéri- 
En 1913 se ocupó de la meningitis cerebroespinal epidémica. Ese año publicó en la Revista Clínica de Madrid un trabajo junto a Ruiz Falcó en el que, según sus observaciones, aquella era una epidemia cuyos primeros brotes habían comenzado a aparecer en Madrid en 191041. Hasta entonces, no se había dado prácticamente ningún caso de esta enfermedad en España. Los autores, al tiempo que describían el cuadro de la enfermedad, reseñaban algunas notas de la historia de la epidemia y su situación por entonces. Es interesante este artículo científico porque da una idea de las condiciones sanitarias e higiénicas del Madrid de la época. En él alertaban de su aparición en los distritos de la zona este de las afueras de la ciudad - Universidad y Tejares de Sixto-, coincidiendo con el recrudecimiento de la epidemia tifoidea en algunos distritos pobres (se referían en concreto a los de Hospital, Latina e Inclusa $)^{42}$. Insistían en que ya en sus comunicaciones en la Academia - como por ejemplo la que presentó en 1912 con el título «Meningitis cerebroespinal epidémica»— habían llamado la atención «sobre la importancia que en la epidemiología de nuestra capital, tienen estos tejares, donde viven hacinados de un modo mísero, muchos trabajadores pobrísimos y gente del hampa ${ }^{43}$. Aunque los casos presentados eran demasiado escasos para considerar la enfermedad como epidemia, sí consideraban necesario estimar la meningitis cerebroespinal contagiosa como dolencia existente en Madrid e informar a los facultativos al respecto. Presentaban entonces, únicamente, los casos que habían tratado en el Hospital General, establecían algunas pautas a seguir en el diagnóstico clínico y bacteriológico y deducían que, probablemente, habría más casos que los tratados por ellos que, o bien no habían sido diagnosticados, o bien no habían sido dados a conocer por los médicos.

El tifus exantemático fue frecuente en Madrid y España a principios del siglo XX. Como señalaba Marañón en su trabajo «Una epidemia de tifus ex-

tos-, aspecto este que, como sabemos, desarrolló de modo prolífico en décadas posteriores. El caso de la fiebre tifoidea porque refleja la audacia con que en ocasiones Marañón trataba sus investigaciones médicas.

41 MARAÑón, G. y Ruiz FAlCó, A. (1913), Sobre la meningitis cerebroespinal contagiosa en España, Revista Clínica de Madrid, marzo, pp. 1-37.

42 Para la cuestión del problema sociosanitario en Madrid, cf. HUERTAS, R. (2002), Vivir y morir en Madrid. La vivienda como factor determinante de salud de la población madrileña (1874-1923), Asclepio, 54 (2), pp. 253-276.

43 HuERTAS (2002), p. 8. La referencia citada corresponde a: MARAÑón, G. (1912), Meningitis cerebroespinal epidémica, Anales de la Real Academia Nacional de Medicina, 30 de marzo, t. 32. 
antemático» ${ }^{44}$; hubo brotes de la epidemia en 1903, 1906, 1909, 1913 y 1916. $\mathrm{Su}$ origen en nuestro país data de la época de los Reyes Católicos cuando los combatientes de Chipre lo trajeron al venir a tomar parte en la guerra de Granada. En centurias pretéritas había existido la confusión en la distinción de la sintomatología del tifus exantemático y de la peste bubónica, en cuya clarificación había jugado un papel fundamental el Dr. Madinaveitia y su equipo. En el Madrid decimonónico había tenido carácter endémico en presidios y barrios de clases humildes. Para la erradicación de este tipo de epidemia era fundamental la higiene pública y privada, y muy en concreto, Marañón apuntaba el beneficio del despiojamiento. Como han señalado recientemente destacados microbiólogos «su descripción del cuadro clínico del tifus exantemático [... es] enormemente precisa [...]. Fue [el doctor] Cortezo el primero que expuso en 1903, en la Conferencia de París, la hipótesis de que el piojo era el agente transmisor, hipótesis probada por Nicolle en 1909. Marañón era un creyente de la teoría del piojo basándose en la gran eficacia del despiojamiento [que, de hecho,...] disminuyó muchísimo el contagio de enfermeras, monjas y médicos» ${ }^{45}$.

Respecto a la fiebre tifoidea, conviene recordar que era una epidemia que se manifestaba en lugares donde se había producido la contaminación de agua y alimentos por materia fecal. Su incidencia era episódica, pero generaba cierta alarma social. Así, puede servir de ejemplo la carta que Marañón envió a su amigo el pintor Ignacio Zuloaga, en diciembre de 1919, en la que comentaba «como siempre exageran por ahí el verdadero estado sanitario de Madrid. Hay bastante tifoidea, pero no más que en cualquier otra capital grande. En la semana pasada han muerto 4 personas de esta enfermedad y en igual tiempo 8 en París. Esto le demuestra a Vd. lo impresionables que aquí somos, pues en París, publican esa cifra, precisamente, como favorable para la salud pública. Hay también mucha gripe, pero en su casi totalidad, leve. En fin, que no deja de haber casos, pero que no hay nada alarmante, nada que justifique el aconsejar a una persona que no venga» ${ }^{46}$. Sobre la cuestión concreta de la fiebre tifoidea, Marañón contradijo en la Academia de la Medicina la teoría entonces más frecuente que defendía el tratamiento de estos enfermos con una alimentación exclusivamente láctea, postulándose en favor de una dieta mixta ${ }^{47}$.

44 MARAÑón, G. (1917), Una epidemia de tifus exantemático en Madrid (Madrid, 1916), con algunas consideraciones sobre el estado actual de la clínica y profilaxia de esta enfermedad, El Siglo Médico, pp. 766-812.

45 Bouzal, Perea, Pizazo de la Garza y Rodríguez-Torres (2003), pp. 379-380.

46 Original Casa Museo Ignacio Zuloaga, Zumaia, Guipúzcoa, copia en FOM.

47 MARAÑón, G. (1920d), La dietética en la fiebre tifoidea, Comunicación presentada en 
Su teoría produjo una gran discusión académica que ocupó varias sesiones donde se discutieron los diferentes argumentos en liza. Lógicamente, Marañón, en todas estas cuestiones, solía documentar sus posiciones con los casos que había visto en la sala de enfermedades infecciosas que dirigía ${ }^{48}$.

Con todo, sus actuaciones más destacadas en el combate contra las enfermedades infecciosas, tuvieron como motivos la pandemia gripal de 1918 -que provocó decenas de millones de muertos en toda Europa- y su preocupación por la expansión endémica de enfermedades en la región extremeña de Las Hurdes. Estas dos cuestiones incidieron de modo decisivo en la popularidad y ascendiente social y político que tuvo el doctor Marañón en años posteriores - no hay que olvidar que fue nombrado consejero de Sanidad en 1919 y de Instrucción Pública en 1920-.

Fue tras el verano de 1918, cuando la Dirección de Sanidad y el Ministerio de la Gobernación, encargaron a los doctores Marañón, Gustavo Pittaluga y Ruiz Falcó un estudio oficial del estado de la pandemia gripal. Con este objetivo, los tres médicos se dirigieron a Francia, buscando estudiar el modo de contención de la gripe que se estaba llevando a cabo en el país vecino. El objetivo del viaje también incluía disipar algunos rumores que por entonces corrían por Madrid acerca de la existencia de otras enfermedades epidémicas existentes en Francia y que serían fácilmente extensibles a España - cólera, tifus exantemático, peste pulmonar-. Allí visitaron diferentes hospitales - Beaujon, SaintAntoine, Val de Gráce, Hotel Dieu, Cochin-, además del Hospital de Infecciosos del Instituto Pasteur. El patólogo Cushing les recomendó visitar la instalación que dirigía el gran bacteriólogo Almroth Wright en Boulogne-sur-mer, ciudad costera situada frente al Canal de la Mancha, donde conocieron al posteriormente célebre Dr. Fleming — además de a otros destacados profesionales como Widal o Babinski-.

la Academia de Medicina, el 5 de junio de 1920, Anales de la Real Academia Nacional de Medicina, t. 40, pp. 368-481. Acerca de esta cuestión cf. BouZAL, PEREA, PiZAZO DE LA GaRZA y RODRÍGUEZ-TORRES (2003), pp. 381-382.

48 Así en estos años se refirió a otras infecciones a las que prestó atención como la escarlatina — cuya epidemia de 1914 en Madrid le llevó a publicar un artículo donde refería los 200 casos que habían visto en su Servicio-, el tétanos, la tuberculosis, la erisipela, etc. Cf. MARAÑóN, G. (1914-1915), Sobre la epidemia de escarlatina en Madrid (1914), Anales de la Academia Médico Quirúrgica, t. 2, pp. 223-234; MARAÑón, G. (1918), Comentarios a una epidemia de erisipela, La Medicina Íbera, t. 2, 21 de febrero y t. III, 6 de abril, también se recoge en Anales de la Real Academia Nacional de Medicina, 1918, t. 38, y en Algunos comentarios a la edición de Mariscal del libro de la peste del Dr. Mercado, El Siglo Médico, 21 de octubre de 1922, t. 70, entre otros. 
Tras su viaje redactaron un informe donde daban cuenta de sus conclusiones a los demás compañeros de profesión, recogido y dado a conocer a la opinión pública a través de las páginas de El Siglo Médico, en los meses finales de $1918^{49}$. La primera conclusión que extraían de su visita era que las formas clínicas de la epidemia de gripe observadas en Francia eran similares a las observadas por Marañón en su Servicio. Por ello, consideraban que «clínica y bacteriológicamente, la epidemia [...] es la misma que existe en España y en el mundo entero, pudiendo afirmar rotundamente que no existe epidemia ni casos aislados de cólera, peste pulmonar, ni tifus exantemático» ${ }^{50}$. Consideraban que no se podía hacer responsable a los poderes públicos encargados de la sanidad de dicha epidemia, pero les incoaban a adoptar las medidas necesarias de desinfección. De este modo, señalaban que las medidas sanitarias dictadas por la Inspección General de Sanidad coincidían con las tomadas en Francia y en el resto de Europa. Tras comparar los datos epidemiológicos de Francia y España señalaban que el factor fundamental que facilitaba el contagio y la propagación de la enfermedad era el hacinamiento y la aglomeración de personas en ambientes confinados.

Como solución proponían una serie de medidas, teóricas y prácticas. Teóricamente el ideal era el diagnóstico precoz y el aislamiento del enfermo. Materialmente esta medida era muy complicada ya que los recursos disponibles en los hospitales eran notablemente insuficientes dado el elevado número de afectados. En la práctica hablaban de lo que se estaba haciendo en Francia donde, como consecuencia de la dificultad añadida por la movilización y la guerra mundial, se había aconsejado limitar el aislamiento a los casos graves con complicaciones pulmonares. Por el contrario, «este criterio, a nuestro entender, no es sostenible desde el punto de vista epidemiológico, puesto que para la difusión de la enfermedad deben ser considerados más peligrosos los casos benignos, que por su misma movilidad van sembrando el contagio por todas partes $\rangle^{51}$. Esa pauta era imposible de realizar en las grandes ciudades españolas, pero sí en agrupaciones reducidas como los destacamentos milita-

49 Marañón, G., Pittaluga, G. y Ruiz Falcó, A. (1918), Informe sobre el actual estado sanitario de Francia y su identidad con la epidemia gripal en España, El Siglo Médico, pp. 916-921. El informe estaba fechado en París en octubre de 1918. Ya anteriormente, este asunto había ocupado a los médicos del país, y así quedó reflejado en la discusión en sesión extraordinaria de la Academia Médico-Quirúrgica, el 13 de junio de 1918, recogida en, La Medicina Íbera, 6 de julio de 1918, t. IV, Madrid.

50 Marañón, PitTaluga y Ruiz Falcó (1918).

51 Marañón, PitTaluga y Ruiz Falcó (1918). Recuérdese que en esta misma línea se expresó en MARAÑóN (1923a). 
res, las asociaciones religiosas, colegios, etc. —como, efectivamente, se había hecho en Francia.

También abordaban medidas concretas, como las que se habían tomado en la frontera para evitar la propagación de la epidemia. En este sentido, consideraban que si bien las desinfecciones individuales en las aduanas eran inútiles, sí era positivo controlar que los grupos de obreros inmigrantes que accedían a España en busca de trabajo - en una Europa asolada, además de por la pandemia, por los efectos de la Primera Guerra Mundial—, se fraccionasen de modo que se evitasen grupos numerosos que, al llegar en condiciones de hacinamiento y de contacto estrecho, eran campo propicio para la extensión de las enfermedades infecciosas. Acerca de los ensayos de vacunación señalaban que estaban aún en un estadio inicial. Aunque anunciaban los avances que el Instituto Pasteur estaba llevando a cabo y que se encaminaban hacia la obtención de una vacuna mixta que consideraban aceptable. Sin embargo, concluían que no había un tratamiento de la gripe que pudiera ser recomendado preferentemente y hacían hincapié en cómo los propios especialistas franceses no se ponían de acuerdo y proponían tratamientos diferentes. Como sabemos, la gripe tendría que esperar muchos años hasta que su etiología fuera clarificada, algo que se lograría en 1933, 1939 y 1950 con las investigaciones de Smith y sus colaboradores, Francis y Taylor, respectivamente.

Años después, en la contestación al discurso de ingreso de Marañón en la Academia de la Historia en 1936, Benigno de la Vega-Inclán relató cómo en función de sus recomendaciones se dieron consejos a la población para prevenir y combatir la enfermedad y, bajo patrocinio de diferentes entidades, se llevaron medicamentos y repartieron fototipias por toda España con orientaciones para combatir el pánico y decaimiento ante la gravedad de la pandemia ${ }^{52}$.

En cualquier caso, la actuación culminante que compendió no sólo la contribución de Marañón a la lucha contra las enfermedades infecciosas, sino la aplicación médica de su pensamiento social en estos años, fue su viaje a Las Hurdes junto a Alfonso XIII en junio de $1922^{53}$.

52 Este discurso está recogido en varias publicaciones, las principales son: (1936) Discurso leído en el acto de su recepción por el Excmo. Sr. D. Gregorio Marañón y contestación del Excmo. Sr. D. Benigno de la Vega Inclán, Madrid, Real Academia de la Historia; (1988), Marañón, actualidad anticipada. Homenaje ofrecido por la Universidad Complutense con motivo del primer centenario de su nacimiento, Madrid, Eudema, pp. 283-311.

53 Para la cuestión de Las Hurdes, cf. Granjel, M. (2003), Las Hurdes. El país de la leyenda. Entre el discurso ilustrado y el viaje de Alfonso XIII, Lleida, ed. Milenio; GRANJEL, M. (1999), Regeneracionismo y medicina en las Hurdes. Las Hurdes como problema sanitario, Medicina e Historia, 2 (cuarta época). Además en 1993 se publicó un compendio documental 
Las Hurdes, lugar prácticamente inaccesible, había sufrido el abandono secular de los gobernantes y había sido objeto del avance de algunas enfermedades endémicas que diezmaban su población. Como se sabe, el conocido como problema de Las Hurdes, había sido objeto de leyendas acerca de su población a lo largo de varios siglos ${ }^{54}$. Entre los avances que se produjeron en la situación de la región hasta 1922, se pueden destacar la construcción de algunos caminos vecinales, la creación de cinco botiquines y el inició de la instalación de la red telefónica ${ }^{55}$.

Fue en abril de 1922, cuando los doctores Gregorio Marañón, José Goyanes - cirujano del Hospital General de Madrid - y Enrique Bardají — inspector de Sanidad de la provincia de Badajoz-, fueron comisionados por el Gobierno para estudiar la situación sanitaria de la región hurdana. En su cuaderno de notas describió Marañón las diferentes comarcas, pueblos, alquerías, etc., que iban atravesando, anotando el aspecto físico, sanitario y ético de las personas que se iban encontrando, las características nutritivas de los habitantes del lugar, los principales alimentos que consumían, la distribución de las casas, sus adornos y las diferentes manifestaciones de enfermedades que se fueron encontrando (paludismo, bocio, cretinismo, hambre crónica, etc.) ${ }^{56}$.

El 10 de junio de 1922, los tres médicos - Marañón, Goyanes y Bardají-, publicaron en La Medicina Íbera un artículo titulado «El problema de Las Hurdes es un problema sanitario ${ }^{57}$. En él aseguraban que si se atajaba la cuestión sanitaria, se lograría una mejora sustancial en la esperanza de vida en la región. La iniciativa para su solución debía ser sostenida, a su juicio, por la Sanidad Pública. La mortalidad de la región — 90 por 1000 - resultaba bo-

de los diferentes artículos, fotografías, opiniones, etc. que suscitó este viaje. Cf. MARAÑón, G. (1993a), Viaje a Las Hurdes. El manuscrito de Gregorio Marañón y las fotografias de la visita de Alfonso XIII, Madrid, El País Aguilar y Fundación Gregorio Marañón.

54 Un excelente resumen acerca de la evolución del interés que Las Hurdes había generado en diferentes personalidades en las décadas pretéritas se encuentra en: CARANDELL, L. (1993), Crónica de las crónicas. En MARAÑóN (1993a), pp. 25-29.

55 Carandell (1993), p. 29.

56 MARAÑÓN (1993a), pp. 59-100. En esta obra se editaron las notas de viaje de Marañón en edición facsímil lo que permite seguir la ruta y su acontecer día a día a lo largo de la Semana Santa de 1922.

57 Bardají, E., Goyanes, J. y Marañón (1922), G., El problema de Las Hurdes es un problema sanitario, La Medicina Íbera, 10 de junio de 1922 (recogido en MARAÑón (1993a), pp. 148-150). Goyanes explicó sus impresiones del viaje — coincidentes con las de Marañón- en GoyAnes, J. (1922), Las Hurdes, baldón de España. (Impresiones de un viaje), Folletones de El Sol, 15 de junio (recogido en MARAÑón (1993a), pp. 167-170). 
chornosa para el país, sobre todo si se tenía en cuenta que en 1922 la mortalidad media de toda España era del 22 por 1000 — según dato aportado por Carandell ${ }^{58}$ - . Los tres médicos cifraban en dos las causas fundamentales del desastre, el paludismo y el hambre crónica, que era conocida como el mal de Las Hurdes. Como solución al paludismo proponían la distribución de quinina y la presencia de médicos en la región. El problema no era geográfico, como solía ocurrir con el paludismo, sino simplemente que «no habiendo en absoluto médicos ni medicinas, cada atacado es un perenne portador de gérmenes y el mosquito encuentra, sin ninguna especie de trabas, un terreno de multiplicación en el organismo de cada habitante» ${ }^{59}$. La cura del paludismo era una necesidad perentoria y paso previo necesario a cualquier otra actuación en la comarca. La segunda causa de la situación hurdana era el hambre crónica. El principal motivo de la hambruna era el problema de comunicación de la región. Así, sucedía con cierta frecuencia que pasaban meses enteros sin que los poblados y alquerías más pobres probasen el pan alimentándose, exclusivamente, de algunos productos de la tierra como nabos, patatas, castañas, etc. El hambre crónica hacía de los habitantes de la zona víctimas de otras enfermedades como la anemia, la tuberculosis y, sobre todo, el bocio y el cretinismo ${ }^{60}$. Unos días más tarde, el 17 de junio de 1922, se publicaba también en La Medicina Íbera, un avance de la Memoria que los tres médicos habían presentado al Gobierno ${ }^{61}$. En sus conclusiones insistían en lo ya señalado y proponían para atajar el problema del hambre enviar periódicamente alimentos de primera necesidad a la zona, sobre todo pan y grasa. También hacían un llamamiento a la construcción de las infraestructuras necesarias que evitasen el aislamiento de la región empleando en las obras a los habitantes de la zona de modo que obtuvieran el jornal diario. Esta mejor comunicación permitiría la explotación de la posible riqueza natural de la región, el traslado de los habitantes de algunas alquerías absolutamente inaccesibles y cuya tierra era totalmente estéril a zonas que facilitasen su adecuada alimentación, la evacuación de los enfermos desahuciados y la organización de la instrucción

58 CARANDELl (1993), p. 24.

59 BARDAJí, GOYANES Y MARAÑóN (1922), p. 149.

60 Como han señalado Francisco Escobar y Gabriela Morreale, desde el punto de vista endocrino este viaje supuso la principal aportación marañoniana en relación a la glándula tiroidea, de la que se ocupó como consecuencia de su análisis del bocio y del cretinismo endémico presente en aquella región. Véase EsCoBAR, F. y Morreale, G. (2003), Marañón y el tiroides. En ROMM, pp. 23-94.

61 BARDAJí, GOYANES y MARAÑóN (1922), pp. 151-154. 
primaria y religiosa ya que, tanto sacerdotes como maestros, podrían atender a varias poblaciones.

Pocos días antes de que el rey visitara la zona, el 3 de junio, la cuestión de Las Hurdes fue debatida en el Congreso de los Diputados. En dicho debate fue Alcalá Galiano, diputado en las Cortes por el distrito cacereño de Hoyos, quien solicitó la adopción de las medidas más urgentes de tipo viario, sanitario y pedagógico ${ }^{62}$. Fruto del mismo, se dotaron las tres plazas médicas que la Memoria de los médicos solicitaban con sus correspondientes botiquines y abundante quinina para atajar los efectos del paludismo ${ }^{63}$. Cuando por fin se aproximaba la visita regia, Marañón advirtió desde las páginas de El Liberal que el rey iba allí «a medir por sí mismo el grado de abandono de unos miles de sus súbditos que hasta ahora no tuvieron con el Estado otro engranaje que el recaudador de Contribuciones. Los que han estado tantos siglos abandonados, deben ahora presentar como un blasón las consecuencias de ese olvido» ${ }^{64}$.

Fue entonces cuando se produjo el famoso viaje de Marañón con Alfonso XIII a la región entre los días 21 y 26 de junio de $1922^{65}$. En él, el rey comprobó personalmente la miseria de los hurdanos. Sin duda, debió ser un viaje durísimo. Como recoge Luis Carandell, el periodista Pedro Antonio Baquerizo, en su crónica para La Correspondencia de España, señaló cómo al penetrar en una vivienda hurdana con evidentes carencias higiénicas, construida en pizarra, sin ventanas y cuya familia compartía el habitáculo con animales, Alfonso XIII exclamó «Es horroroso. Ya no puedo ver más» ${ }^{66}$.

Entre las principales consecuencias que tuvo aquel viaje real es indicativa la carta que, poco después, Pedro Segura, Obispo de Coria - futuro Arzobispo de Sevilla y Cardenal-, dirigió al Rey expresándole las necesidades de Las Hurdes ${ }^{67}$. Tras mostrar su satisfacción por la excursión regia pidió, entre

62 Diario de Sesiones del Congreso de los Diputados, 3 de junio de 1922, recogido en MARAÑÓN (1993a), pp. 191-196.

63 Un pormenorizado estudio sobre el problema del paludismo es el de RoDRíGUEZ OCAÑA, E. et al. (2003), La acción médico-social contra el paludismo en la España metropolitana y colonial del siglo XX, Madrid, CSIC.

64 Marañón, G. (1993b), El rey a Las Hurdes, El Liberal, 6 de junio de 1922. En MARAÑÓN (1993a), p. 147.

65 El ya citado libro Viaje a Las Hurdes, recoge todos los detalles y algunas fotografías que reflejan imágenes del histórico viaje de Alfonso XIII a la comarca. Véase MARAÑóN (1993a), pp. 101-144.

66 CARANDELl (1993), p. 32.

67 Segura, P. (1922), Del Obispo de Coria al Rey, El Debate, 29 de junio. Recogido en MARAÑÓN (1993a), pp. 174-176. 
otras cosas, además de lo que los médicos solicitaban en su Memoria, que se abonase a las madres que habían acogido expósitos el dinero que adeudaba la Diputación Provincial - en torno a 30.000 pesetas-, que se acabara con la usura, que se condonara al menos una parte de las contribuciones e impuestos y que se creara una cooperativa de consumo con precios moderados, una Comisaría Regia y un hospital para la región. Entre las medidas que, efectivamente, se adoptaron, cabe destacar, en primer lugar, la prohibición de la adopción de expósitos. En este sentido, se daba la doble paradoja de que, por un lado, las madres hurdanas tenían a los expósitos en igual o mejor consideración que sus propios hijos, pues aquéllos les generaban unos ingresos indispensables, $y$, por otro, la llegada de esta sangre nueva a la región había facilitado la supervivencia de aquellas gentes condenada a la endogamia. Y, en segundo lugar, la creación del Patronato de Las Hurdes que trató de ir cubriendo las necesidades más perentorias de la región. Sus miembros fueron, además del mismo Rey, el Obispo de Coria, el ministro de la Gobernación, Marañón, Goyanes, y otros más. Su creación y acción sirvió para sensibilizar a la opinión pública ante la situación de la región y contribuyó a erradicar la visión legendaria que se tenía de esa región y sus habitantes. Sin embargo, pronto se vio politizada. La acción del Directorio Militar de Primo de Rivera y la enemistad personal de Marañón con Martínez Anido - ministro de la Gobernación del Directorio desde 1923 y vicepresidente desde 1925-, llevó al médico a no asistir a dicho Patronato, que vio así a uno de sus principales impulsores neutralizado.

La evolución posterior de la región no estuvo exenta de polémica. Sin duda, el caso más conocido es el del famoso documental realizado durante los años de la II República por el joven Luis Buñuel ${ }^{68}$. En él mostraba que, diez años después del viaje del rey, la miseria seguía siendo el elemento definitorio de la región. Sin embargo, aunque no lo pareciera, la mejora de la situación se fue llevando a cabo paulatinamente. En este sentido, se puede destacar el testimonio de Maurice Legendre. Fruto del paso de muchos meses de su vida en la comarca, presentó su tesis doctoral acerca de la situación de la región, en la Universidad de Burdeos ${ }^{69}$. Legendre defendía que los hurdanos, lejos de ser oprobio nacional, representaban una página más de la epopeya

68 El documental de Luis Buñuel Tierra sin pan vio la luz en 1932.

69 Marañón publicó una tercera en $A B C$, elogiando la tesis doctoral de Legendre y en donde destacaba que con ese trabajo académico, la cuestión de Las Hurdes se convertía en algo universal y científico, dejando de ser algo humillante para la nación española. Véase MARAÑóN, G. (1928), Las Hurdes en la Universidad francesa, $A B C, 6$ de enero. 
española. Pues bien, dos décadas más tarde, en 1944, Legendre en su artículo Recuerdos de Las Jurdes ${ }^{70}$, realizó una visión retrospectiva de la transformación de la comarca a lo largo de las tres últimas décadas. Allí señalaba algunos avances concretos en la región como la mejora de las comunicaciones, la edificación de viviendas, la presencia de Guardia Civil, la acción sanitaria, el aumento del rendimiento agrícola, la desaparición del paludismo y el hambre endémica o la mejora educativa. Sin ser un paraíso, no cabe duda que aquel viaje cambió el futuro de la región y, más de medio siglo más tarde, como señaló Carandell, la región había perdido «sus tristes connotaciones, en parte gracias a la sensibilización que produjeron aquellos viajes, hay una tierra que la acción de los gobiernos y la tenacidad de sus hijos han convertido en una región más de Extremadura y de España» ${ }^{71}$.

\section{LA DICTADURA PRIMORRIVERISTA: EPÍLOGO DE UNA ACTUACIÓN}

En los años posteriores Marañón continuó prestando atención a la cuestión sociosanitaria y a la lucha contra las enfermedades infecciosas pero ese interés se vio seriamente afectado por motivos políticos. En ello influyó decisivamente la implantación en España de la Dictadura de Primo de Rivera (1923-1930). La llegada al poder del militar produjo que en esos años y la actividad pública de Marañón asistiera a una creciente politización, lo que también tuvo repercusión sobre su actividad médica.

La ruptura de Marañón con el Directorio fue temprana. En noviembre de 1923, Marañón envió una carta abierta al Dr. José Boullón Cavezudo donde criticaba la situación sanitaria española y la disposición del Gobierno hacia ella. En ella se mostraba pesimista acerca de lo que el régimen militar pudiera hacer respecto al estado de las cosas:

el Directorio, a pesar de cuanto se diga y se crea, no puede hacer transformaciones hondas y esenciales en ningún aspecto de la vida nacional, sino sólo programas mínimos y concretos, deshaciendo o modificando "hechos aislados", pero nada más. Y la reforma sanitaria que se le propone [una comisión creada para el análisis de la situación], supone tal revolución social, financiera, técnica y aún psi-

70 Legendre, M. (1944), Recuerdos de Las Jurdes, Revista LAR, 10, 11 y 12. Recogido en MARAÑÓN (1993a), pp. 177-187.

71 Carandell (1993), p. 25. 
cológica, que es ilusorio pensar en implantarla como quien cambia la decoración del primer acto por la del segundo ${ }^{72}$.

Para iniciar la reforma sanitaria necesaria, Marañón proponía, como primer paso, una serie de pequeñas medidas que impidiesen los abusos, olvidos, injusticias o faltas de celo profesional de los médicos. Más concretamente, apostaba por obligar a los médicos a declarar los casos que conociesen de infecciosos, luchar contra la viruela mediante vacunación universal impuesta, extinguir focos de tifoidea en pueblos donde era infección endémica obligando a la vacunación y a la higiene hídrica-, o rehacer el sistema de prevención y tratamiento de la tuberculosis, entre otras cosas.

Marañón tenía una impresión pesimista sobre el futuro. Además, la dimisión de Martín Salazar como ponente de la comisión nombrada para analizar la situación sanitaria del país y establecer las medidas a adoptar para mejorarla le hacían temer un serio retroceso en aspectos sanitarios. En su ya abierta oposición a la Dictadura señalaba su «propósito de re[strin]gir toda colaboración en los asuntos de la Sanidad pública, mientras no tenga alguna garantía de que ello no signifique, tan rotundamente como ahora, perder el tiempo» ${ }^{73}$.

Ciertamente, Marañón desarrolló una actividad docente y científica verdaderamente extraordinaria en estos años. Tan es así, que no sólo hoy nos sorprende lo prolijo de su obra sino que también el mismo Santiago Ramón y Cajal, en 1929, al recibir varios trabajos suyos, sentenciaba, «atraviesa V. una fiebre de actividad supraintensiva, polivalente y fecundísima. Asombra como puede V., atender conjuntamente con el Servicio del Hospital y su copiosa clientela, a tantos requerimientos periodísticos y lo que es más notable, que tenga tiempo para escribir prólogos y admirables libros de vulgarización científica henchidos de datos y de observaciones y críticas originales ${ }^{74}$. Su trabajo continuó radicado, además de en su consulta privada, en el Departamento de Patología Médica - a través del cual estuvo vinculado a la Universidad Central- y en la Academia de Medicina ${ }^{75}$. En la organización del Departamento de Patología Médica influyó su experiencia de años atrás y los viajes

72 Marañón, G. (1923b), Carta abierta, Unión Médica, 7 noviembre, t. II, año IX, n. ${ }^{\circ}$ 274, pp. CCLXXI-CCLXXIII (fondos bibliográficos del CIB).

73 MARAÑón (1923b). En el artículo aparece regir, en vez de restringir, debe ser una errata.

74 FOM, Signatura 7-17.

75 Así, en la Academia de Medicina hasta el estallido de la guerra civil española en 1936, presentó más de setenta comunicaciones donde, además de cuestiones endocrinas, presentó nuevas áreas de su actividad clínica e investigadora, entre las que destacaban las de temática sexual. 
que había realizado al extranjero para estudiar el modus operandi de algunos hospitales europeos en aras a colaborar en la estructuración del nuevo Hospital del Rey (como, por ejemplo, el viaje que le llevó a Alemania en 1920) ${ }^{76}$.

Fue la inauguración de este Hospital del Rey el que causó el paulatino alejamiento de Marañón de la actividad relativa a las patologías infectocontagiosas y cuando vemos aminorar sus testimonios desde la perspectiva médico-social vinculada a las mismas. Desde años atrás, Marañón venía colaborando en la construcción de ese nuevo Hospital del Rey ${ }^{77}$, llamado de Enfermedades Infecciosas en época republicana. Aquel hospital tenía la impronta de Marañón. Como han señalado sus discípulos, su intervención en la construcción fue determinante, singularmente en las ideas que aportó al arquitecto para su planificación ${ }^{78}$. En 1924, poco antes de ser inaugurado, fue destituido del cargo de director para el que había sido propuesto. Su destitución, además de tener amplia repercusión en el medio intelectual, causó malestar entre el gremio médico. Entre éstos, Marañón comentó lo sucedido, entre otros, con los doctores catalanes Augusto Pi I Sunyer y Ramón Turró. A éste, le agradeció su apoyo «en unos días amargos pues el General M[artín]ez. Anido, me ha destituido de mi cargo de director del Hospital para Infecciosos, obra mía, como parida por mí, en 12 años de trabajo iporque recibo cartas de

76 El Departamento de Patología Médica estaba organizado de modo que facilitaba las labores clínicas, académicas y de investigación que allí se desarrollaban. Dividido en tres plantas, el piso bajo era policlínico y en él se encontraban las secciones de cirugía, aparato respiratorio, metabolismo, nutrición, sistemas nerviosos constitutivos, reumatismo, cardiología, rayos-X, fisioterapia, ginecología, dermatología, urología, otorrinolaringología y odontología. En la primera planta había dos salas para pacientes femeninas (veinte camas en cada una de las salas), además de un servicio de rayos-X y un aula de conferencias. En la segunda planta se situaban otras dos salas para pacientes varones, además de la biblioteca, un laboratorio y el departamento de aparato digestivo. Anejo al edificio se encontraba el Laboratorio Central, el de Medicina Experimental y el de Química Biológica. Allí, trabajó junto a sus discípulos y dirigió diferentes investigaciones. Por sus aulas aparecieron importantes figuras del panorama científico nacional e internacional que, invitados por Marañón, impartieron conferencias.

77 Porras Gallo, M. ${ }^{a}$. (1993), El Hospital del Rey de Madrid. En GonZÁlez DE PABLO, A. y MARTínez PÉreZ, J., Historia de los hospitales. Hospitales relevantes en España, El Médico (coleccionable n. ${ }^{\circ}$ 46). Hay también dos tesis de doctorado no publicadas: SÁENZ VALIENTE, P. (1977), Las Enfermedades transmisibles en el Hospital Nacional de Enfermedades Infecciosas, UCM y GÁlvez RuIZ, A. (2009), Enfermedades infecciosas y práctica clínica en la España del siglo XX: una aproximación a través de las historias clínicas del Hospital del Rey de Madrid (1924-1950), UCM.

78 (1935), Veinticinco años de labor, pp. 11-15. 
Unamuno! Siento el malestar de la coz en el corazón!» ${ }^{79}$. Efectivamente, Unamuno y Marañón se habían convertido en baluartes de la oposición a la Dictadura de Primo de Rivera. Si el primero fue abocado al exilio, el segundo acabó en la cárcel con motivo de la Sanjuanada en la que fue injustamente inculpado. Todavía un año más tarde, Marañón replicaba desde las páginas de El Sol la declaración de varios médicos en las páginas de La Medicina Íbera señalando que él era el director idóneo para el nuevo hospital:

[...] Yo no tengo palabras para encarecer mi gratitud a los buenos compañeros que de modo tan cariñoso y espontáneo suponen que debiera reanudarse mi relación, hace ya un año rota, con el Hospital del Rey, que creó el entusiasmo del Dr. Martín Salazar y en cuya erección puse yo tanto tiempo y tanto entusiasmo. Pero me importa declarar que mi voto es completamente contrario a la opinión que ellos tan amistosamente defienden. En España hay personas perfectamente capacitadas para dirigir el Hospital de infecciosos, y es de esperar que, a pesar del absurdo método con que las están buscando [oposiciones, es conocida la radical oposición de Marañón a este sistema], las encuentren. Estoy convencido de que la utilidad de mi gestión alcanzó su máximo en la tarea constructiva, que está ya terminada, y, sobre todo, en la labor pedagógica de diez años, que espero continuar en mi otro Hospital, en el General, donde trabajé hasta ahora y del que hubiera tenido el dolor de separarme, si no me hubiese sido arrebatada la dirección del de Epidemias. Lo importante es crear lo que se pueda, en un país como este, donde está casi todo por hacer; y yo tengo más vocación, por ahora, de continuar armando nuevos tinglados, que de reposar en el perfeccionamiento tranquilo de un objeto ya logrado ${ }^{80}$.

Como queda dicho, Marañón continuó su trabajo científico - ya al margen del Hospital del Rey_, en su Departamento de Patología Médica. También sus discípulos han señalado como no recibieron ayuda oficial para la dotación de este Departamento, cuyo pabellón se renovó y amplió sucesivamente hasta 1931 gracias al impulso, también económico, del mismo Marañón ${ }^{81}$. Fue entonces, en el verano de ese año de 1931, cuando recién llegada la II República, fue nombrado catedrático de Endocrinología ${ }^{82}$.

79 Fundación Gregorio Marañón. Marañón a Ramón Turro. Signatura 4-37. Copia procedente de la Biblioteca de Cataluña.

80 Esa carta se reprodujo en El Siglo Médico, que es de donde se extrae. (1925), El Siglo Médico, Año LXXII, t. 76, p. 380.

81 (1935), Veinticinco años de labor.

82 Orden de 4 de julio de 1931. Ministerio de Instrucción Pública y Bellas Artes, sección Universidades. Cf. AGA. Educación. Legajo 15050/12). GómEZ-SANTOS (2001), pp. 344-346, relata estos acontecimientos. 


\section{CONCLUSIÓN}

La profundización en aspectos escasamente contemplados con anterioridad en la obra de Marañón como los relativos a sus puntos de vista sobre las cuestiones de índole social relacionadas con las enfermedades infecciosas, muestran una rica complejidad que enriquece un perfil científico al que se le ha dado un mayor relieve en lo tocante a otro tipo de aspectos de su actividad profesional, especialmente su aportación a la Endocrinología y a otros campos afines como la divulgación científica sobre estos y otros temas llevadas a cabo a finales de los años veinte en obras como Tres Ensayos sobre la vida sexual o Gordos y flacos (ambas publicadas en 1926)-.

En el período situado en las décadas de 1910 y 1920, Marañón se ocupó de modo muy particular de las enfermedades infecciosas y de sus causas sociales en un sentido muy amplio, tomando como ejemplo representativo la situación sociosanitaria de Madrid. Como se ha visto en las páginas precedentes, la influencia que su protagonismo en este área tuvo sobre su ascendencia social no fue desdeñable, con dos momentos álgidos: su viaje a Francia en 1918 junto a Ruiz Falcó y Pittaluga y su visita en compañía de Alfonso XIII a la región extremeña de Las Hurdes en junio de 1922. Si bien su participación en ambos acontecimientos era bien conocida, en este artículo se ha tratado de mostrar cómo su actuación en esas coyunturas respondía a una preocupación continuada de Marañón por la lucha contra las enfermedades infecciosas y por la situación sociosanitaria que se prolongó hasta finales de los años veinte, cuando sus circunstancias personales, en especial su oposición la régimen primoriverista, y su consiguiente alejamiento profesional de la dirección del Hospital del Rey, junto a otros factores, disminuye su producción y su actividad directa y explícita en estos temas.

Recibido: 10 de mayo de 2008.

Aceptado: 20 de enero de 2010. 